\title{
Assessing the pros and cons of vaginal birth after caesarean relative to elective repeat caesarean section
}

\author{
Sangeeta G. Prasad*, Preeti Malhotra
}

Department of Obstetrics and Gynecology, American International Institute of Medical Sciences, Udaipur, Rajasthan, India

Received: 15 February 2020

Accepted: 11 March 2020

\section{*Correspondence:}

Dr. Sangeeta G. Prasad,

E-mail: neelugupta417@gmail.com

Copyright: (C) the author(s), publisher and licensee Medip Academy. This is an open-access article distributed under the terms of the Creative Commons Attribution Non-Commercial License, which permits unrestricted non-commercial use, distribution, and reproduction in any medium, provided the original work is properly cited.

\begin{abstract}
Background: Recent years have witnessed a rise in rate of primary caesarean section (CS). No. of women reporting with a previous CS scar is also increasing. Judicious trial of labor in such patients can prevent repeat caesarean section. Aim of this study was to assessing the safety and success rate of vaginal birth after caesarean (VBAC) in selected cases of patients who have undergone previous lower segment CS (LSCS) is the main aim of this study.

Methods: In this prospective observational study carried out in a tertiary care teaching hospital over a period of 1 year. 375 pregnant women with a history of one previous LSCS for non-recurrent indications were enrolled. The statistical technique of t-test was administered for relative comparison with respect to maternal and neonatal complications across the two groups, i.e. repeat LSCS and vaginal delivery.

Results: Out of 375 patients 187 patients $(49.9 \%)$ underwent elective LSCS for recurrent indication and for nonrecurrent indication associated with some complicating factor. Trial of labor in $188(50.10 \%)$ was given out of which $59.3 \%$ had spontaneous vaginal delivery, $7.20 \%$ had instrumental delivery and $33.50 \%$ landed into emergency CS. Commonest cause of Em. LSCS being Fetal distress. As regards maternal complications, no statistically significant difference was found between the Repeat LSCS and Vaginal delivery groups $(\mathrm{t}=0.779, \mathrm{p}>0.05)$. On similar lines, there was no statistically significant difference across both groups as regards neonatal complications $(\mathrm{t}=0.632, \mathrm{p}>$ $0.05)$.

Conclusions: Taking into account the increased trend of primary CS, trial of VBAC in selected cases is very important. It can be concluded that VBAC has chances of success in cases with previous one LSCS but it must be carefully investigated and monitored.
\end{abstract}

Keywords: Elective caesarean section, Lower segment cesarean section, Vaginal birth after cesarean section

\section{INTRODUCTION}

To start with, this paper is hinged on the dictum as quoted by the eminent Edwin Bradford Cragin, an obstetrician in 1916 that is, - "Once a caesarean, always a caesarean" and it is true historically. ${ }^{1,2}$ But now there are other perspectives that call in for discussion and so it has formed the crux of this research study. Of late there has been a rapid increase in the rate of $\mathrm{C}$-section, in India and world across, which may be unwarranted despite the medical complications that might ensue after the $\mathrm{C}$ section. The World Health Organization has stated that caesarean rates higher than $10-15 \%$ indicate unnecessary maternal risk. This paper also presents a critique analyzing the risks and benefits associated with VBAC. It argues the case in point whether vaginal birth after CS (VBAC) might help in reducing the rates of C-section.

All post caesarean pregnancies do not require repeat CS and a majority of them may have uncomplicated vaginal 
delivery. In fact, a trial of vaginal birth after a previous $\mathrm{CS}$ (VBAC) is considered safer than a routine repeat CS. VBAC has distinct advantages over a repeat CS. However, in cases of failed trial of labor there are increased chances of maternal and perinatal morbidity \&mortality. However, trial of labor is also not bereft with complications which should be taken into account. Basic prerequisite being the availability of a well-equipped emergency care in order to deal with any risk /complications which might arise during trial of labor.

The pertinent implication for practitioners is to answer the question as to whether a previous caesarean is a medical indication for a repeat caesarean. And if the answer is "NO" then, what is the prerequisites for successful subsequent deliveries in such cases. It is for the physicians to predict the cases for VBAC based on evaluation of factors that significantly influence the risk of failed attempted VBAC, such as, obstetric history, e.g. uterine scar type (lower segment/classical), uterine closure technique (single/double layer closure), number of previous caesareans. The indication for caesarean, prior vaginal births, interval between 2 deliveries, and maternal age, in addition to other factors, such as current labor management, including induction or augmentation of prostaglandins or oxytocin. ${ }^{2-4}$

In view of this, trial of vaginal delivery in women with post caesarean pregnancy remains controversial and continuous critical audit of the trends is imperative. Women and their relatives should be informed and counselled regarding the safety and the risk involved in both the modes of delivery'.

\section{Risks and benefits as per delivery method}

\section{Benefits of $V B A C$}

Women who choose VBAC compared to Elective repeat $\mathrm{CS}$ have reported greater satisfaction with their delivery, which is attributed to feelings of selflessness quicker recovery time from VBAC has been reported. ${ }^{5}$ Maternal morbidity and mortality associated with VBAC is also low.

A successful VBAC also increases the probability of future vaginal deliveries. ${ }^{6}$ Less maternal depression has been reported with vaginal deliveries. ${ }^{5}$ Additionally, successful lactation is more likely with VBAC.

\section{Benefits of elective CS}

Elective CS can be scheduled at a convenient time; hence the outcome is more certain and there is less painful delivery.

The parents can schedule days off from work. ${ }^{5}$ Since 30 $50 \%$ of VBAC land up in repeat caesarean if trial of labor fails, so many expectant mothers and obstetricians opt for elective caesarean rather than facing the risk an emergent caesarean, which is more dangerous than planned caesareans

For women elective caesarean is theorized to be protective for the pelvic floor. However, this is controversial, because pregnancy itself predisposes to pelvic floor weakness and not the method of delivery. But the most important advantage is avoidance of risk of scar rupture. The true risk of scar rupture with VBAC is uncertain as many factors affect it. Several studies have been done to examine risk factors and predictors of uterine scar rupture in pregnancies following prior caesarean deliveries, however clear correlations have proven elusive. $^{7}$

\section{Risk to fetus in VBAC}

VBAC has a times higher risk of perinatal deaths as compared to elective CS but this risk is shown to be equivalent to that of a fetus of a primigravida mother. ${ }^{8,11}$ The absolute risk being 4.5 per 10,000 births and with wide confidence limits. Risk of neonatal birth trauma and postpartum hemorrhage if operative vaginal delivery, like vacuum or forceps assisted delivery is required is increased. Rates of wet lung syndrome and neonatal convulsions are lesser in such deliveries. ${ }^{9}$

\section{METHODS}

In order to examine the potential cases for successful VBAC after the first caesarean, an examination was conducted for 375 women with previous one lower segment caesarean section (LSCS) in time period of $18^{\text {th }}$ May 2018 to $31^{\text {st }}$ May 2019. The statistical technique of paired t-test was run to relatively assess the neonatal complications and maternal complications across the two groups i.e. repeat LSCS and vaginal delivery.

Patient selection was guided by both medical and nonmedical grounds and it included factors, such as incision type, and number of previous caesarean sections, physical factors such as cervical ripening, effacement, and progress of labour, and obstetric history like gravidity, parity, and prior vaginal delivery. ${ }^{8,10}$

Certain non-medical factors which were taken into account include, preference of patients, provider comfort regarding the mode of delivery. If during trial of labour there was any suspicion of scar dehiscence or fetal distress or if progress of labour was unsatisfactory, then trial was abandoned. All women were always prepared for emergency $\mathrm{CS}$, if need arose.

Complete history including indication of previous CS, intra and postoperative complications during previous surgery, the details of the present pregnancy, scar tenderness and any other disorder were recorded. However, those who had presented with intrauterine fetal death, two previous CS and scar of other uterine surgery were excluded from the study. Women with recurrent 
indications for CS or those having non recurrent indications with any complicating factors in present pregnancy were taken for elective LSCS $(n=188)$. Those women with previous one LSCS for the non-recurrent indications were given a trial for vaginal delivery $(\mathrm{n}=$ 197).

Case selection for the trial for vaginal delivery was done as per ACOG guidelines

- $\quad$ Singleton pregnancy

- Gestational age $>34$ weeks

- History of previous one LSCS

- Non recurrent indication for the previous LSCS.

\section{The labor was monitored with}

- Maternal vital parameters were monitored hourly particularly pulse and BP

- Fetal heart rate monitoring by intermittent auscultation - every 15 minutes in the first stage and every 5 minutes in second stage of labor

- Progress of labor as per WHO partograph

- A close watch for the early recognition of scar dehiscence by identifying signs such as maternal tachycardia, vaginal bleeding, scars tenderness and fetal distress.

Attempt at vaginal delivery was abandoned if there was any suspicion of scar dehiscence or fetal distress or unsatisfactory progress of labor. All women were always prepared for emergency CS if need arose.

\section{RESULTS}

During the period of study, a total of 375 women with previous one CS were included in the study protocol. Looking into the previous details and present findings, in $188(50.10 \%)$ women (Table 1) vaginal delivery was contemplated and in 187 (49.9\%) women elective CS was planned.

Table 1: Distribution of the cases.

\begin{tabular}{|l|l|l|}
\hline $\begin{array}{l}\text { Category of female } \\
\text { respondents }\end{array}$ & Frequency & Percentage \\
\hline Vaginal delivery & 188 & $50.10 \%$ \\
\hline Elective CS & 187 & $49.90 \%$ \\
\hline Total & $\mathbf{3 7 5}$ & $\mathbf{1 0 0 . 0 0 \%}$ \\
\hline
\end{tabular}

Table 2: Age group.

\begin{tabular}{|l|l|l|}
\hline Age group & Frequency & Percentage \\
\hline $21-25$ & 83 & $22.1 \%$ \\
\hline $26-30$ & 239 & $63.7 \%$ \\
\hline $31-35$ & 39 & $10.4 \%$ \\
\hline More than 35 & 14 & $3.7 \%$ \\
\hline Total & $\mathbf{3 7 5}$ & $\mathbf{1 0 0 . 0 \%}$ \\
\hline
\end{tabular}

Table 2 shows the demographic profile in terms of age group. It was found that most of the women $(63.7 \%)$ belong to 26-30 years of age. Further, from Table 3, it can be inferred from the above table that majority of the women delivered at the gestational age of 37-40 weeks $(77.6 \%)$

Table 3: Gestational age.

\begin{tabular}{|l|ll|}
\hline $\begin{array}{l}\text { Period of gestation } \\
\text { (weeks) }\end{array}$ & Frequency & Percentage \\
\hline $34-37$ & 72 & $19.2 \%$ \\
\hline $37-40$ & 291 & $77.6 \%$ \\
\hline More than 40 & 12 & $3.2 \%$ \\
\hline Total & $\mathbf{3 7 5}$ & $\mathbf{1 0 0 . 0} \%$ \\
\hline
\end{tabular}

Table 4: Indications for previous caesarean delivery.

\begin{tabular}{|l|ll|}
\hline $\begin{array}{l}\text { Indications for previous } \\
\text { caesarean delivery }\end{array}$ & Frequency & Percentage \\
\hline Cephalopelvic disproportion & 155 & $41.3 \%$ \\
\hline Fetal distress & 79 & $21.1 \%$ \\
\hline Non progression of labor & 39 & $10.4 \%$ \\
\hline Malpresentation & 34 & $9.1 \%$ \\
\hline Ante partum hemorrhage & 18 & $4.8 \%$ \\
\hline Failed trial & 19 & $5.1 \%$ \\
\hline Failed induction & 9 & $2.4 \%$ \\
\hline Obstructed labor & 9 & $2.4 \%$ \\
\hline BOH & 13 & $3.5 \%$ \\
\hline Total & $\mathbf{3 7 5}$ & $\mathbf{1 0 0 . 0} \%$ \\
\hline
\end{tabular}

Table 5: Mode of delivery in trial of labor group $(\mathbf{n}=\mathbf{1 8 8})$.

\begin{tabular}{|lll|}
\hline Mode of delivery & Frequency & Percentage \\
\hline Spontaneous vaginal & 111 & $59.30 \%$ \\
\hline Instrumental & 14 & $7.20 \%$ \\
\hline Emergency repeat LSCS & 63 & $33.50 \%$ \\
\hline Total & $\mathbf{1 8 8}$ & $\mathbf{1 0 0 . 0 0 \%}$ \\
\hline
\end{tabular}

Table 6: Indications of repeat emergency LSCS (63 cases).

\begin{tabular}{|lll|}
\hline $\begin{array}{l}\text { Indication of repeat } \\
\text { emergency LSCS }\end{array}$ & Frequency & Percentage \\
\hline Fetal distress & 27 & $42.86 \%$ \\
\hline Non progress of labour & 22 & $34.92 \%$ \\
\hline Scar tenderness & 10 & $15.87 \%$ \\
\hline Abruptio placenta & 4 & $6.35 \%$ \\
\hline Total & $\mathbf{6 3}$ & $\mathbf{1 0 0 . 0 0 \%}$ \\
\hline
\end{tabular}

It can be inferred from Table 4 that major indications for previous caesarean delivery included Cephalopelvic disproportion $(41.3 \%)$, fetal distress $(21.1 \%)$, nonprogression of labor $(10.4 \%)$, malpresentation $(9.1 \%)$, failed trial $(5.1 \%)$ and ante partum hemorrhage (4.8\%). Table 5 show that $66.5 \%$ women delivered vaginally in the trial group; $59.30 \%$ had spontaneous vaginal delivery 
and $7.2 \%$ women had to undergo instrumental delivery by outlet forceps or vacuum extraction. The study indicated that the common causes for abandoning the trial of labor and opting for emergency LSCS (Table 6) was fetal distress (42.86\%), non-progress of labor $(34.92 \%)$, scar tenderness $(15.87 \%)$ and abruptio placenta $(6.35 \%)$.

Table 7. Maternal complications.

\begin{tabular}{|lll|}
\hline $\begin{array}{l}\text { Type of } \\
\text { complication }\end{array}$ & $\begin{array}{l}\text { Repeat LSCS } \\
\text { group }\end{array}$ & $\begin{array}{l}\text { Vaginal delivery } \\
\text { group }\end{array}$ \\
\hline Pyrexia & 2 & 1 \\
\hline $\begin{array}{l}\text { Postpartum } \\
\text { hemorrhage }\end{array}$ & 3 & 2 \\
\hline Wound gap & 1 & 0 \\
\hline $\begin{array}{l}\text { Cervical/vaginal } \\
\text { tear }\end{array}$ & 0 & 4 \\
\hline Haematuria & 1 & 0 \\
\hline Total & 7 & 7 \\
\hline
\end{tabular}

A relative comparison on maternal complications across the two groups i.e. repeat LSCS and vaginal delivery (Table 7) indicate that pyrexia, PPH, wound gape, haematuria were more in repeat LSCS group while cervical/vaginal tears, traumatic $\mathrm{PPH}$ and scar complications were more common in the VBAC group. Further analysis in this study using t-test was conducted to examine the difference of both the group cases, i.e. Repeat LSCS group and the Vaginal delivery group w.r.t Maternal complications (Table 8). The findings show that there was no statistically significant difference between the repeat LSCS group and the vaginal delivery group w.r.t maternal complications $(\mathrm{t}=0.779, \mathrm{p}>0.05)$.

A relative comparison w.r.t Neonatal complication indicates that asphyxia was more common in the vaginal delivery group (Table 9) as compared to the Repeat LSCS group. NICU admissions were more common in the repeat LSCS group (cause being fever, birth asphyxia and jaundice but all babies were discharged in good condition) than in the vaginal delivery group.

Further analysis to examine the difference of both the group cases, i.e. repeat LSCS group and the vaginal delivery group w.r.t neonatal complications (Table 10) using t-test revealed that there was no statistically significant difference in neonatal complications across both the groups $t=0.632, p>0.05$.

Table 8: t-test.

\begin{tabular}{|lll|llllllll|}
\hline & $\begin{array}{l}\text { Levene's test } \\
\text { for equality of } \\
\text { variances }\end{array}$ & \multicolumn{7}{c|}{ t-test for equality of means } \\
& F & Sig. & T & df & $\begin{array}{l}\text { Sig. (2- } \\
\text { tailed) }\end{array}$ & $\begin{array}{l}\text { Mean } \\
\text { difference }\end{array}$ & $\begin{array}{l}\text { Std. error } \\
\text { difference }\end{array}$ & $\begin{array}{l}\text { 95\% confidence interval } \\
\text { of the difference }\end{array}$ \\
\hline & & & & & & & & Lower & Upper \\
\hline $\begin{array}{l}\text { Equal variances } \\
\text { assumed }\end{array}$ & 0.035 & 0.854 & 0.779 & 12 & 0.451 & 0.57143 & 0.73309 & -1.02583 & 2.16869 \\
\hline $\begin{array}{l}\text { Equal variances } \\
\text { not assumed }\end{array}$ & & & 0.779 & 11.772 & 0.451 & 0.57143 & 0.73309 & -1.02927 & 2.17213 \\
\hline
\end{tabular}

Table 9: Neonatal complications.

\begin{tabular}{|ll|l|}
\hline $\begin{array}{l}\text { Neo natal } \\
\text { complications }\end{array}$ & Repeat LSCS & $\begin{array}{l}\text { Vaginal } \\
\text { delivery group }\end{array}$ \\
\hline Fever & 2 & 2 \\
\hline Asphyxia & 1 & 4 \\
\hline Septicaemia & 1 & 1 \\
\hline Jaundice & 3 & 2 \\
\hline Total & $\mathbf{7}$ & $\mathbf{9}$ \\
\hline
\end{tabular}

\section{DISCUSSION}

This study represents our observations over a period of one year. Women with prior one LSCS require special management, both during the antenatal period and during labour. The decision for a trial of labor or the elective repeat LSCS in a patient needs to be based on proper selection of cases and after thorough counseling. Rough idea can be made on the basis of maternal characteristics and obstetric history.

Several studies suggest that for appropriately selected women with previous one LSCS, a trial for vaginal delivery is safe. Published literature shows that there has been a $60-80 \%$ success in VBAC. ${ }^{1,11,12}$ The study success rate $(66.5 \%)$ is comparable to these studies. Factors that negatively influence the likelihood of successful VBAC are believed to be cases with labor induction and augmentation, maternal obesity, gestational age $>40$ weeks, birth weight $>4000$ gm and inter delivery interval of less than 19 months. ${ }^{2,13}$ A history of a previous successful VBAC increases the likelihood for success with future attempts. ${ }^{6}$

The risk of uterine rupture is higher with an induced labor than with a spontaneous labor with trial. ${ }^{11,13}$ Induction and augmentation with oxytocin is safe in selected cases 
with standard obstetric indications; but use of prostaglandins for induction needs much caution. Bujold E et al have reported that the single layer closure of the previous lower segment incision was associated with a fourfold increase in the risk of uterine rupture compared with a double layer closure. ${ }^{14}$

Table 10: t-test on neonatal complications between the test groups.

\begin{tabular}{|l|lllllllll|}
\hline & $\begin{array}{l}\text { Levene's test } \\
\text { for equality of } \\
\text { variances }\end{array}$ & \multicolumn{1}{l}{ t-test for equality of means } \\
& F & Sig. & t & Df & $\begin{array}{l}\text { Sig. (2- } \\
\text { tailed) }\end{array}$ & $\begin{array}{l}\text { Mean } \\
\text { difference }\end{array}$ & $\begin{array}{l}\text { Std. error } \\
\text { difference }\end{array}$ & $\begin{array}{l}\text { 95\% confidence interval } \\
\text { of the difference }\end{array}$ \\
\hline & & & & & & & & Lower & Upper \\
\hline $\begin{array}{l}\text { Equal variances } \\
\text { assumed }\end{array}$ & 0.086 & 0.78 & -0.632 & 6 & 0.55 & -0.5 & 0.79057 & -2.43445 & 1.43445 \\
\hline $\begin{array}{l}\text { Equal variances } \\
\text { not assumed }\end{array}$ & & & -0.632 & 5.602 & 0.552 & -0.5 & 0.79057 & -2.46829 & 1.46829 \\
\hline
\end{tabular}

Neither repeat cesarean delivery nor trial of labor is risk free. Maternal morbidity in terms of pyrexia, atonic $\mathrm{PPH}$, hematuria, and wound gape are more common in repeat $\mathrm{CS}$ group, while cervical and vaginal tear, traumatic $\mathrm{PPH}$ and uterine scar problems are more common in trial of vaginal delivery. However, the difference in maternal morbidity rate is not statistically significant, this is evident in our study also. ${ }^{15-17}$ A trial of vaginal delivery may result in small but insignificant increase in the perinatal morbidity and mortality rates, which can be reduced by proper selection of cases. ${ }^{15-17}$

\section{CONCLUSION}

Prediction as to whether the trial of labor will succeed or not and to identify patients who are at risk of failing the trial of labor is very important. Many repeat CS can be avoided if proper selection of cases, proper timing and close supervision of labor by competent staff. There is a need for individualized approach to all the cases.

Funding: No funding sources

Conflict of interest: None declared

Ethical approval: The study was approved by the Institutional Ethics Committee

\section{REFERENCES}

1. Ugwumadu A. Does the maxim "once a caesarean, always a caesarean" still hold true? PLoS Med. 2005;2(9):e305.

2. Hibbard JU, Gilbert S, Landon MB, Hauth JC, Leveno KJ, Spong CY, et al. Trial of labor or repeat cesarean delivery in women with morbid obesity and previous cesarean delivery. Obstet Gynecol. 2006;108(1):125-33.

3. Flamm BL, Goings JR, Liu Y, Wolde-Tsadik G. Elective repeat cesarean delivery versus trial of labor: a prospective multicenter study. Obstet Gynecol. 1994;83:927-32.
4. O'Brien-Abel N. Uterine rupture during VBAC trial of labor: risk factors and fetal response. J Midwifery Women's Health. 2003;48(4):249-57.

5. Cox KJ. Counseling women with a previous cesarean birth: toward a shared decision-making partnership. J Midwifery Womens Health. 2014;59(3):237-45.

6. Gyamfi C, Juhasz G, Gyamfi P, Stone JL. Increased success of trial of labor after previous vaginal birth after cesarean. Obstet Gynecol. 2004;104(4):715-9.

7. Eden KB, McDonagh M, Denman MA, Marshall N, Emeis $\mathrm{C}, \mathrm{Fu} \mathrm{R}$, et al. New insights on vaginal birth after cesarean: can it be predicted? Obstet Gynecol. 2010;116(4):967-81.

8. Smith GC, Pell JP, Cameron AD, Dobbie R. Risk of perinatal death associated with labor after previous cesarean delivery in uncomplicated term pregnancies. JAMA. 2002;287(20):2684-90.

9. Rietveld AL, Kok N, Kazemier BM, de Groot CJ, Teunissen PW. Trial of labor after cesarean: attempted operative vaginal delivery versus emergency repeat cesarean, a prospective national cohort study. J Perinatol. 2015;35(4):258-62.

10. Studsgaard A, Skorstengaard M, Glavind J, Hvidman L, Uldbjerg N. Trial of labor compared to repeat cesarean section in women with no other risk factors than a prior cesarean delivery. Acta Obstet Gynecol Scand. 2013;92(11):1256.

11. Dhillon BS, Chandhiok N, Bharti S, Bhatia P, Coyaji $\mathrm{KJ}$, Das $\mathrm{MC}$, et al. Vaginal birth after cesarean section (VBAC) versus emergency repeat cesarean section at teaching hospitals in India: an ICMR task force study. Int J Reprod Contracept Obstet Gynecol. 2014;3:592-7.

12. Flamm BL, Goings JR, Liu Y, Wolde-Tsadik G. Elective repeat cesarean delivery versus trial of labor: a prospective multicenter study. Obstet Gynecol. 1994;83(6):927-32.

13. Chhabra S, Arora G. Delivery in women with previous cesarean section. J Obstet Gynaecol India. 2006;56:304-7. 
14. Bujold E, Bujold C, Hamilton EF, Harel F, Gauthier RJ. The impact of a single layer or double layer closure on uterine rupture. Am J Obstet Gynecol. 2002;186:1326-30.

15. Shah SR, Prasad P. Outcome of labor in previous one lower segement cesarean section cases. Asian J Obstet Gynecol Pract. 2006;10:7-11.

16. Dodd J, Crowther C. Vaginal birth after cesarean versus elective repeat cesarean for women with a single prior cesarean birth: a systemic review of the literature. Aust NZJ Obstet Gynaecol. 2004;44:38791.
17. Hutton EK. Elective repeat caesarean delivery versus trial of labor: a meta-analysis of the literature from 1989 to 1999. Am J Obstet Gynecol. 2000;183:118797.

Cite this article as: Prasad SG, Malhotra P. Assessing the pros and cons of vaginal birth after caesarean relative to elective repeat caesarean section. Int J Reprod Contracept Obstet Gynecol 2020;9:1350-5. 